\title{
THE EFFECTS OF NORMAL HORSE SERUM ON THE IN VITRO ACTIVITY OF TYROTHRICIN ${ }^{1}$
}

\author{
BY ROBERT J. REEDY AND STANLEY W. WOLFSON
}

(From the Food and Drug Administration, Federal Security Agency, Washington, D. C.)

Tyrothricin, discovered by Dubos, is an antibiotic product of Bacillus brevis. Its antibacterial action against a wide variety of Gram-positive organisms can be demonstrated by both in vitro and in vivo tests. As a therapeutic agent, it has been restricted to topical use because of its inherent toxicity on parenteral administration.

Tyrothricin is composed of two fractions, gramicidin and tyrocidine. Except in relatively large amounts tyrocidine has little or no activity against most of the Gram-positive bacteria. On the other hand, gramicidin in very minute amounts exerts a marked antibacterial activity against many of these organisms, and is therefore largely responsible for the major activity of tyrothricin.

As tyrothricin is used in the form of ointments, emulsions, troches, etc. for topical therapy, and as there is some controversy in the literature concerning the effect of serum on the bacteriostatic efficacy of this antibiotic, it seemed desirable to investigate the extent of its reduced activity, if any, in the presence of serum. Dubos (1) stated that the effect of gramicidin is inhibited "only to a small extent by serum, tissue exudates or peptones." Rammelkamp (2), however, noted that serum, exudates and feces markedly inhibit the activity of tyrothricin, and that approximately 100 times the amount of this antibiotic was required to exert an anti-streptococcal activity in their presence. Hotchkiss (3) reported that gramicidin is mildly inhibited by the presence of serum, but that tyrocidine possesses little activity in its presence. Henderson (4) noted that gramicidin, in contrast to tyrocidine, is not affected by soluble proteins, such as serum albumin, "in any concentration," in fact "its activity seems enhanced by serum albumin," a statement he attributes to Dubos.

\footnotetext{
1 Presented at the Second National Symposium on Recent Advances in Antibiotics Research held in Washington, D. C., April 11-12, 1949, under the auspices of the Antibiotics Study Section, National Institutes of Health, Public Health Service, Federal Security Agency.
}

\section{METHODS}

In our tests, two organisms and three media were employed. The organisms were Streptococcus fecalis (M-19) and Micrococcus pyogenes var. aureus (F.D.A. No. 209). The fecal streptococcus was selected for its high degree of sensitivity to this antibiotic, and $S$. aureus for its prevalence in skin lesions. Three broth media chosen for their different nutritive qualities were used: Edamin (0.8\%), Bacto Peptone $(1.0 \%)$, and Bacto Brain Heart Infusion (3.7\%). Cultures in these media incubated at $37^{\circ} \mathrm{C}$. were transferred daily, and $1 \%$ suspensions utilized in the assay inoculum. The method used for testing the sensitivity of the organisms to tyrothricin was a decimal dilution technic ${ }^{2}$ where varying amounts of an alcoholic solution of tyrothricin were brought into direct contact with the organisms suspended in the assay broths. Bacteriostatic endpoints were determined by visual inspection of the tubes for presence or absence of growth. The tyrothricin used was the accepted standard composed of a mixture of $80 \%$ crystalline tyrocidine hydrochloride and $20 \%$ crystalline gramicidin in a concentration of $5 \mathrm{mgms}$. per $\mathrm{ml}$., dissolved in $95 \%$ ethyl alcohol. In the assay, the volume of alcohol never exceeded $0.2 \mathrm{ml}$. per $5 \mathrm{ml}$. of broth to eliminate the possibility of alcohol affecting the growth of the organisms. All titrations were made in triplicate. In certain instances, where high concentrations of tyrothricin were employed with the fecal streptococcus in the presence of $5 \%$ serum, the endpoints could not be determined with any degree of accuracy because of the presence of a precipitate. In such cases the endpoint was determined by the use of a brom thymol blue indicator, growth being indicated by an alkaline reaction. When it became necessary to determine bacteriostasis with the staphylococcus under the same conditions, a nitrate reduction method (5) was employed, growth being indicated by a positive color reaction for nitrite.

\section{RESULTS}

Figure 1 illustrates the minimal inhibitory concentrations of tyrothricin required for the two organisms in the three media with and without serum. It can be noted that in the absence of serum the amounts of tyrothricin necessary to cause complete inhibition of $S$. fecalis were 0.01 microgram when Edamin was employed, and 0.1 microgram when both Bacto Peptone and Bacto

2 This information will be published in the near future. 
INFLUENCE OF SERUM ON THE BACTERIOSTATIC ENDPOINTS OF TYROTHRICIN

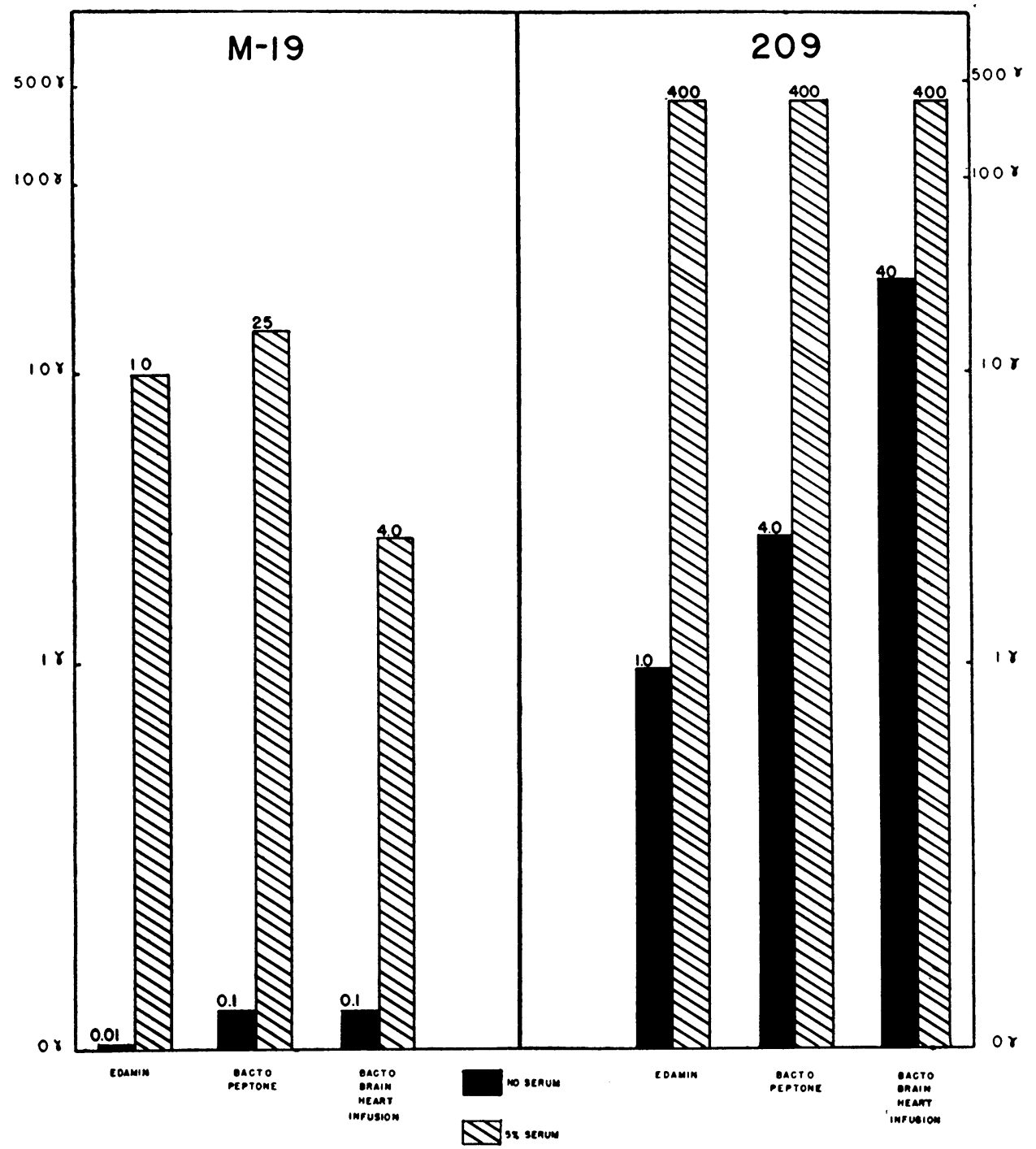

Fig. 1. Influence of Serum on the Bacteriostatic Endpoints of Tyrothricin

Brain Heart Infusion broths were used. Upon the addition of $5 \%$ normal horse serum to the Edamin broth, it was necessary to use 1,000 times (10.0 micrograms) as much tyrothricin to produce the same degree of bacteriostasis. When serum was added to Bacto Peptone, the amount of tyrothricin necessary to produce the same degree of bacteriostasis was increased 250 fold $(25.0 \mathrm{mi}$ crograms). A 40 -fold increase in the amount of tyrothricin was required to produce bacteriostasis in the presence of serum with the Bacto Brain Heart Infusion broth (4.0 micrograms). As will be noted in Figure 1, the staphylococcus proved to be approximately 150 times more resistant to the action of tyrothricin than the fecal streptococcus. In spite of this, however, the addition of serum markedly increased the amount of tyrothricin necessary to produce bacteriostasis.

Both crystalline gramicidin and crystalline tyrocidine have been tested for their bacteriostatic activity in Edamin broth with and without 5\% serum. The streptococcus was inhibited by 20.0 micrograms of tyrocidine in the absence of serum while 200 micrograms were required when serum 
was present. On testing the gramicidin fraction with this organism 0.002 microgram was found to be necessary to achieve bacteriostasis in the absence of serum. In its presence, the streptococcus required 2.0 micrograms. Unusual results were obtained when the staphylococcus was tested with tyrocidine. It was found that this fraction was not inhibited by the presence of serum at a concentration of 300 micrograms or more. This amount of tyrocidine was. the minimum amount necessary to produce bacteriostasis in the presence and absence of serum. A similar effect was not noted for the gramicidin fraction, however, as 0.2 microgram was required in the absence of serum while 80 micrograms were necessary in its presence.

\section{DISCUSSION}

In demonstrating the sensitivity of these organisms to the components of tyrothricin (gramicidin and tyrocidine) it was found that in Edamin broth the fecal streptococcus exhibited a susceptibility to 0.002 microgram of crystalline gramicidin. Its growth was unaffected by 15.0 micrograms of crystalline tyrocidine in this medium. The staphylococcus showed a sensitivity to 0.2 microgram of crystalline gramicidin yet resisted 300 micrograms of crystalline tyrocidine. Because of the vast differences in sensitivity of these organisms to the two components of tyrothricin, any effect of serum on this antibiotic can only be demonstrated by its action on the gramicidin fraction. Although the loss of activity of tyrothricin is attributed to the interference with the gramicidin fraction, there is some indication, however, that when large concentrations (400 micrograms or more) of tyrothricin are present, the tyrocidine fraction may play an important part in antibacterial activity. Although, contrary to reports, we have shown the activity of gramicidin to be greatly reduced by as little as $\mathbf{5 \%}$ serum, it cannot be definitely stated that this is entirely due to the direct effect of serum on the gramicidin. From the figures obtained there is some evidence that the serum possibly supplied an added growth factor that might have played a part. Whatever the reason, it is a fact that serum does greatly reduce the activity of tyrothricin tested in vitro. It may well be inferred, therefore, that in the presence of undiluted serum exuding from a trauma, where only a thin film of applied tyrothricin is permitted to come into direct contact, its antibiotic activity may be reduced to a point of minor therapeutic value.

\section{SUMMARY AND CONCLUSIONS}

It has been shown that the addition of $5 \%$ normal horse serum markedly reduced the activity of tyrothricin. The amount of tyrothricin necessary to inhibit the test organisms was markedly influenced by the composition of the medium. From the data obtained it can be concluded that the effective component of tyrothricin is gramicidin. Contrary to published reports, we have found that in inhibitory concentrations tyrocidine is not affected by serum when the test organism is Staphylococcus aureus.

\section{BIBLIOGRAPHY}

1. Dubos, R. J., Bacteriostatic and bactericidal agents obtained from saprophytic microorganisms. J. Pediat., 1941, 19, 588.

2. Rammelkamp, C. H., Use of tyrothricin in the treatment of infections. War Med., 1942, 2, 830.

3. Hotchkiss, R. D., Advances in Enzymology. 1944, 4, 153-199. Interscience Publishers, Inc., N. Y.

4. Henderson, John, The status of tyrothricin as an antibiotic agent for topical applications. J. Am. Pharm. A., 1946, 25, 141.

5. Randall, W. A., and Reedy, R. J., A simple method for determining bacterial reduction of nitrates. J. Lab. \& Clin. Med., 1939, 25, 315. 